\title{
Pharmacological modulation of anti-tumor immunity induced by oncolytic viruses
}

\section{Nicole E. Forbes ${ }^{1,2}$, Ramya Krishnan ${ }^{1,2}$ and Jean-Simon Diallo ${ }^{1,2} *$}

${ }^{1}$ Center for Innovative Cancer Research, Ottawa Hospital Research Institute, Ottawa, ON, Canada

2 Faculty of Medicine, University of Ottawa, Ottawa, ON, Canada

\section{Edited by:}

Volker Schirrmacher, DKFZ, Germany

Reviewed by:

Pier Paolo Claudio, Marshall

University, USA

Jianping Huang, University of Florida, USA

\section{*Correspondence:}

Jean-Simon Diallo, Center for Innovative Cancer Research, Ottawa Hospital Research Institute, 501

Smyth Road, Ottawa, ON K1J 8L6,

Canada

e-mail: jsdiallo@ohri.ca
Oncolytic viruses (OVs) not only kill cancer cells by direct lysis but also generate a significant anti-tumor immune response that allows for prolonged cancer control and in some cases cures. How to best stimulate this effect is a subject of intense investigation in the OV field. While pharmacological manipulation of the cellular innate anti-viral immune response has been shown by several groups to improve viral oncolysis and spread, it is increasingly clear that pharmacological agents can also impact the anti-tumor immune response generated by OVs and related tumor vaccination strategies. This review covers recent progress in using pharmacological agents to improve the activity of OVs and their ability to generate robust anti-tumor immune responses.

Keywords: Oncolytic virotherapy, anti-tumor immunity, cancer, combination therapy, pharmacological therapy, chemotherapy, immuno-modulatory therapy
INTRODUCTION: ONCOLYTIC VIRUSES: MULTI-MECHANISTIC BIOTHERAPEUTICS AGAINST CANCER

Oncolytic viruses (OVs) are self-amplifying biotherapeutics that have been selected or engineered to preferentially infect and kill cancer cells. Generated from a multitude of viral species, OVs exploit cancer-associated cellular defects arising from genetic perturbations including mutations and epigenetic reprograming [reviewed in Ref. (1)]. Among others, these cellular defects lead to dysfunctional anti-viral responses and immune evasion, increased cell proliferation and metabolism, and leaky tumor vasculature (2). These characteristics in turn provide a fertile ground for viral replication and subsequent lysis of tumor cells and permit the growth of genetically attenuated OVs that are otherwise harmless to normal cells.

In addition to the direct killing of cancer cells, OVs can also trigger a potent anti-tumor immune response. Infected tumor cells induce the release of pro-inflammatory cytokines and expose both viral and tumor-associated antigens to patrolling immune cells, promoting the differentiation of antigen-presenting cells and T-cell activation (3-5). How much tumor infection and lysis are necessary to trigger these responses remains a topic of debate; however, it is clear that the combination of direct oncolysis and activation of anti-tumor immunity can lead to durable cures in pre-clinical mouse models of cancer.

A number of OVs are currently being evaluated in clinical trials to treat a range of cancer types. For a more comprehensive overview, the reader is invited to consult an excellent review by Russell et al. (6). Of particular note, herpes simplex virus-1 (HSV-1), vaccinia virus, reovirus, and adenovirus-based OV strains have made the most progress toward approval (710). Shanghai Sunway Biotech's oncolytic adenovirus (H101), deleted for the viral E1B gene and thought to target p53 deficient cancer cells, was the first approved OV in China as early as 2005, indicated for head and neck cancers. (11). Profound tumor regression is common following treatment with OVs; for example, durable objective responses were observed in 3/14 patients (hepatocarcinoma, lung cancer, and melanoma) following treatment with vaccinia virus JX-594 in a phase I trial (7). This virus has been deleted for viral thymidine kinase (TK), making it dependent on cellular TK that is overexpressed in cancer cells (7). In addition to the TK deletion that provides tumor selectivity, the virus also expresses granulocyte macrophage colony-stimulating factor (GM-CSF) to stimulate anti-tumor immunity. Most recently, Amgen's HSV-1-based talimogene laherparepvec (T-VEC) led to $16 \%$ durable response in a phase III clinical trial for late-stage melanoma, and it is expected that the company will file for FDA approval in North America in the coming year $(12,13)$. Like JX-594, T-VEC expresses GM-CSF but has deletions in viral genes ICP34.5 and ICP47 that confer tumor selectivity and promote antigen presentation, respectively (14).

While widespread approval and clinical implementation of oncolytic virotherapy are in the foreseeable future, heterogeneity in clinical response to OVs remains a significant challenge as evidenced from a number of early and late-stage human clinical trials $(6,15,16)$. This heterogeneity in response can be attributed to factors that impact OV delivery and spread within tumors, such as pre-existing immunity and remnant tumor anti-viral responses, as well as to a variably immunosuppressive tumor microenvironment that can prevent the generation of an effective anti-tumor immune response. To overcome these challenges, it has been long recognized in the OV field that improvements to therapeutic efficacy either through viral engineering or through combination therapies will be critical $(6,17)$. In the current review, we will focus on advances in therapeutic strategies employing small-molecule pharmacological agents that ameliorate OV treatment in vivo by manipulating the innate and/or adaptive immune response to virus and tumor (summarized in Table 1). 
Table 1 | Combinations of pharmacological and oncolytic therapies with demonstrated improvements in in vivo treatment efficacy

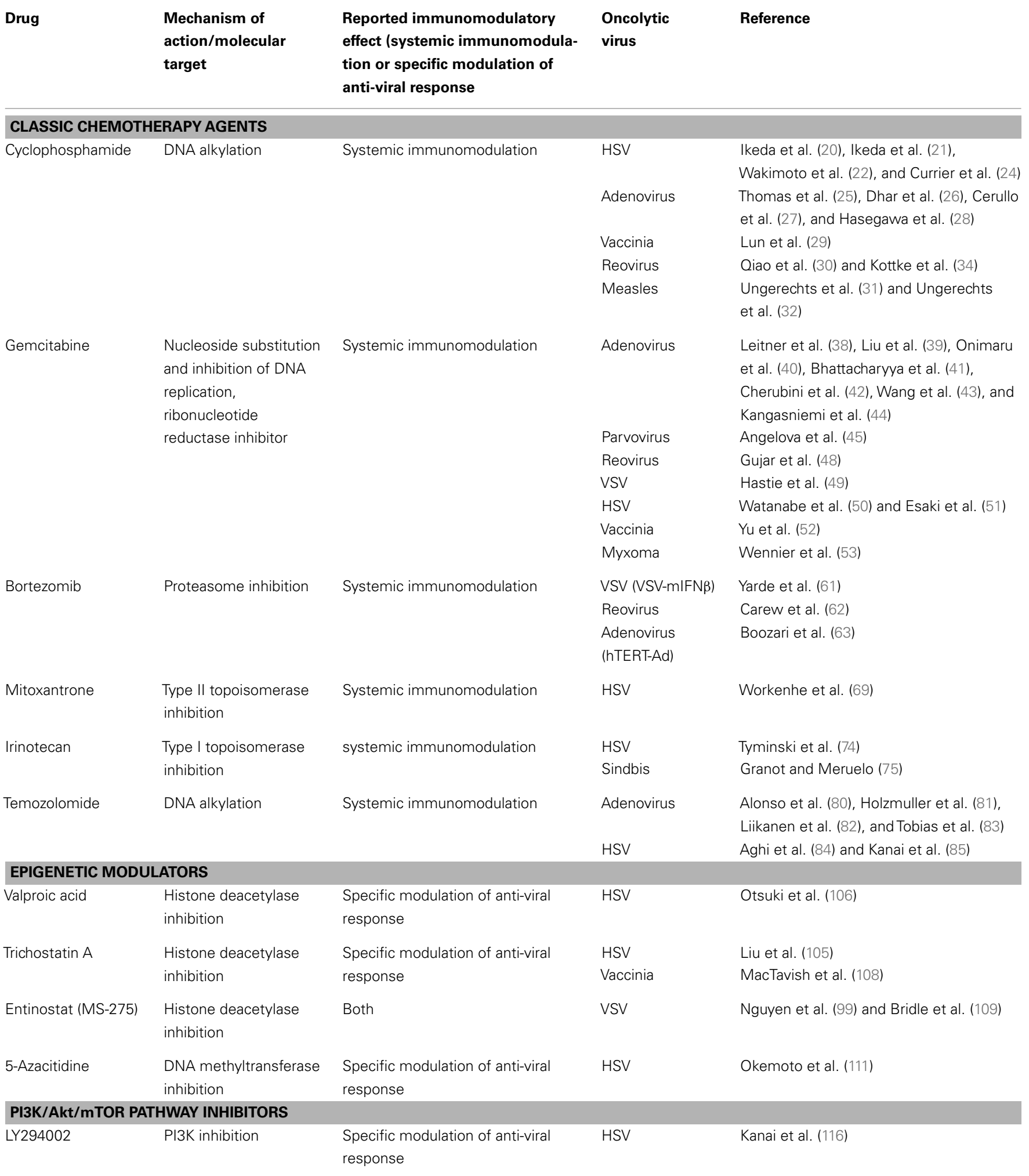


Table 1 | Continued

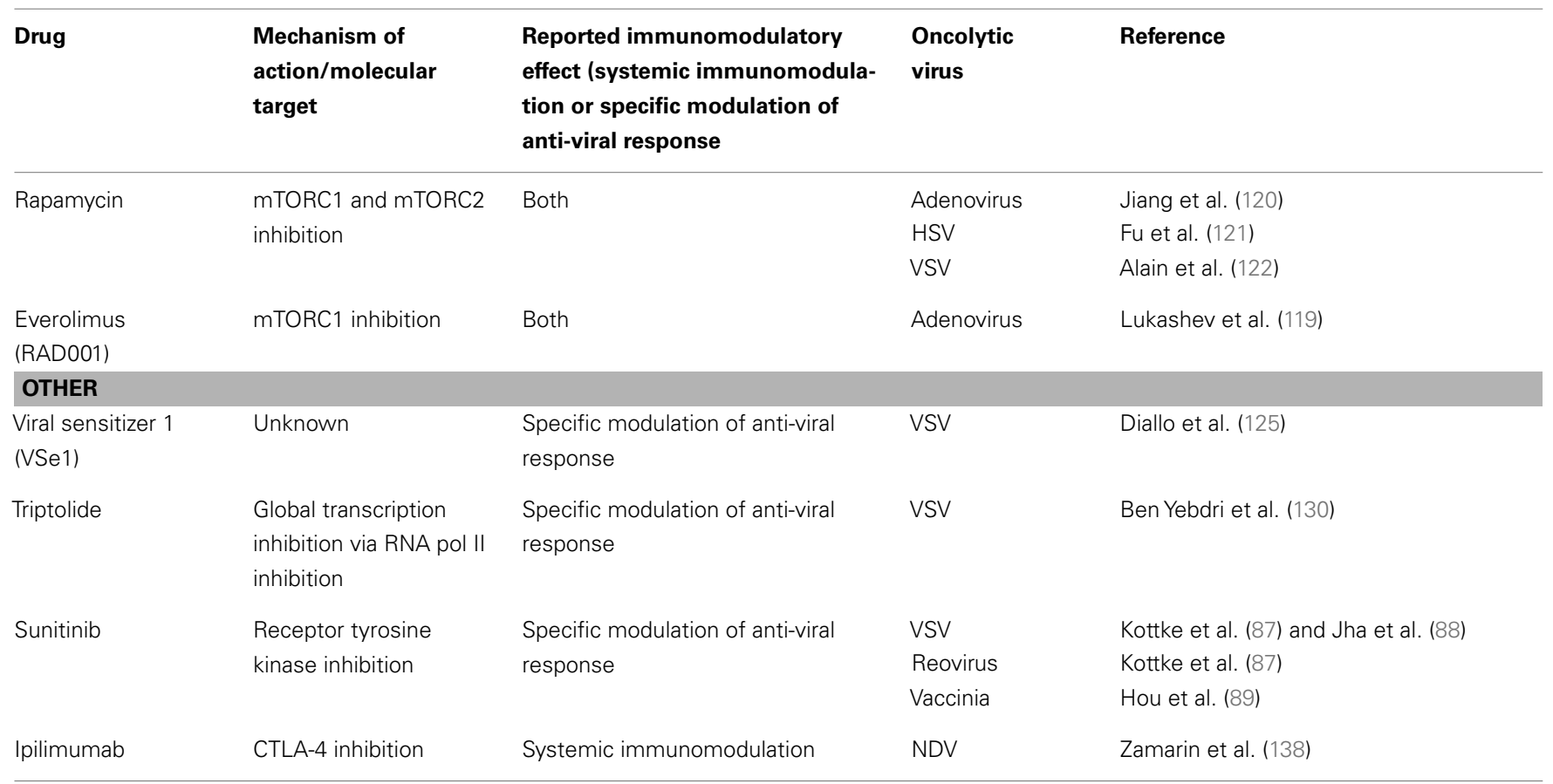

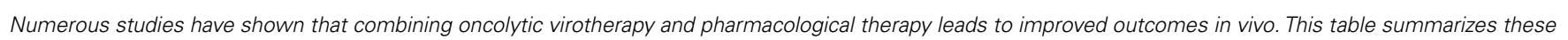

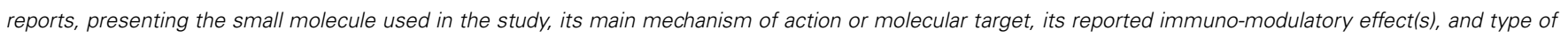

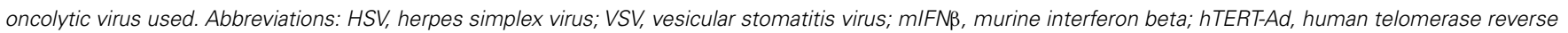

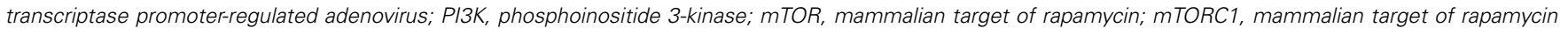
complex 1; mTORC2, mammalian target of rapamycin complex 2; CTLA-4, cytotoxic T-lymphocyte antigen 4.

\section{STANDARD CHEMOTHERAPEUTIC DRUGS THAT BOOST OV ACTIVITY THROUGH SYSTEMIC EFFECTS ON IMMUNE CELLS AND THE IMMUNE RESPONSE}

Most cancer patients with advanced disease will be subjected to some form of chemotherapy. This will largely depend on the type of cancer and other salient pathophysiological characteristics. Given that most patients enrolled in clinical trials to test the efficacy of OVs suffer from advanced disease (7), a natural trend in the OV field has been to test OVs in combination with chemotherapeutics that are currently the standard of care. Classic chemotherapy drugs typically capitalize on the fact that cancer cells are continuously replicating unlike most normal cells (18). However, some normal cell types have higher replication rates, leading to significant off-target effects. Hematopoietic cells among others can be affected and this can lead to systemic immunosuppression (discussed below). While the evaluation of chemotherapeutic drugs in the context of OV therapy has been fairly empirical for the most part, their immunosuppressive effects can inherently complement OV activity by increasing OV spread within tumor beds and/or increasing anti-tumor immune responses. The following sections provide an overview of classic chemotherapy drugs that have been evaluated in combination with OVs focusing on their anti-cancer mechanism of action, examples of OVs with which they have been tested, and the mechanism by which these agents suppress immunity and co-operate with OVs to improve therapeutic outcomes.

\section{CYCLOPHOSPHAMIDE}

Cyclophosphamide (CPA) is a nitrogen mustard alkylating agent that leads to cross-linking of nucleotides. Its active metabolite, phosphoramide mustard, interferes with DNA replication by forming guanine-to-guanine intra-strand and inter-strand crosslinks (19). Aldehyde dehydrogenase (ALDH) catalyzes the conversion of the immediate precursor of phosphoramide mustard, aldophosphamide, to an inactive metabolite. Normal cells, for example intestinal epithelial cells and bone marrow stem cells, have a high level of ALDH, protecting them from the effects of CPA's toxic metabolites. In contrast, some lymphocytes have a lower level of ALDH, which makes them more susceptible to the effects of CPA. CPA has been used in combination with several OVs including HSV-1 (20-24), adenovirus (25-28), vaccinia (29), reovirus (30), measles (31-33), and vesicular stomatitis virus (VSV) (33), leading to improved anti-tumor activity in vivo. Several studies suggest that CPA can be efficacious in combination with OVs by preventing immune-mediated viral neutralization through inhibiting or delaying the rise of neutralizing antibodies and depleting anti-viral immune cells including natural killer (NK) cells, monocytes, macrophages, and lymphocytes (20, 22, 23, $25,26)$. For example, one study showed that CPA inhibits tumor infiltration of innate phagocytes (macrophages, microglia, and NK cells) following HSV treatment in a syngeneic rat glioma model, leading to increased viral persistence and improved overall efficacy (23). Other studies suggest CPA can also enhance the generation of 
anti-tumor immunity by inhibiting regulatory T-cells (Tregs) (27, 34). Results from a first in-human clinical trial using Ad-GM-CSF (CGTG-102) to treat solid tumors suggest that metronomic dosing of CPA decreases Tregs without compromising the induction of anti-tumor T-cell responses. This was found to be associated with increased cytotoxic T-cell responses and the induction of Th1 type immunity in most patients. The best progression-free survival and overall patient survival rates were seen with the combination of metronomic CPA and intratumoral infection of adenovirus (27).

\section{GEMCITABINE}

Gemcitabine is a fluorinated deoxycytidine nucleoside analog. Incorporation of this analog into DNA prevents further addition of nucleosides during DNA polymerization and thereby halts DNA replication and cell division. Gemcitabine also binds irreversibly to the active site of ribonucleotide reductase. As a result, nucleotide production is halted and DNA replication ceases, leading to apoptosis in rapidly dividing cells [reviewed in Ref. (35)]. While gemcitabine can decrease neutralizing antibodies similar to CPA (36), it is thought to promote anti-tumor immune responses by off-target elimination of myeloid derived stem cells (MDSCs), which suppress T-cell responses. Gemcitabine treatment thereby increases the activity of $\mathrm{CD} 4+$ and $\mathrm{CD} 8+\mathrm{T}$-cells that recognize tumor antigens (37). This drug has been shown to increase the anti-tumor activity of a wide array of OVs including adenovirus (38-44), parvovirus $(45,46)$, reovirus $(47,48)$, VSV (49), $\operatorname{HSV}(50,51)$, vaccinia (52), and myxoma virus (53). In the latter example, the anti-cancer activity of oncolytic myxoma virus was improved using gemcitabine in disseminated pancreatic cancer murine models (53). Interestingly, no sensitization occurred in immunocompromised mice, supporting the requirement for a virus-triggered anti-tumor immune response in mediating the combination effect. The combination of gemcitabine and reovirus was recently evaluated in a phase I clinical trial and while antitumor immune responses were not measured, neutralizing antibodies against reovirus were decreased by gemcitabine treatment. In this study, $80 \%$ of evaluable patients showed either partial response or stable disease (36).

\section{BORTEZOMIB}

Bortezomib is a proteasome inhibitor approved to treat multiple myeloma and mantle cell lymphoma. It reversibly binds the catalytic site of the $26 \mathrm{~S}$ proteasome with high affinity and specificity (54). Bortezomib has been shown to inhibit NF- $\kappa \mathrm{B}$ by preventing degradation of I $\mathrm{B}$ - $\alpha$ in some cell types (55) although the opposite effect has also been observed (56). Other mechanisms of action by which bortezomib may kill cancer cells are through ER-stress and activation of the unfolded protein response (UPR) (57) and triggering apoptosis by preventing the degradation of pro-apoptotic proteins $(56,58)$. Some studies have shown that treatment of cancer cells using bortezomib increases surface expression of Hsp90 and Hsp60 in cancer cells leading to their more effective phagocytosis by dendritic cells (DCs), improving tumor vaccine effects (59). Bortezomib-treated mice also exhibit increased DC maturation and phagocytic potential (59). On the other hand, one study found that bortezomib treatment leads to apoptosis of allo-reactive CD4+ T-cells. Thus the net result on anti-cancer and anti-viral immune responses is likely context-dependent (60).

Bortezomib has been tested in combination with oncolytic VSV (61), reovirus (62), and adenovirus (63). Using VSV-mIFN $\beta$, combined treatment with bortezomib was inhibitory to virus replication in myeloma cells in vitro but led to improved therapeutic efficacy compared to single treatments in syngeneic murine myeloma models (61). Given no observed effect on tumor viral load, this suggests bortezomib likely increases virus-induced cell death and/or potentiates the anti-tumor response mediated by the virus. Supporting the former, in combination with the oncolytic adenovirus hTERT-Ad, bortezomib enhanced infection-induced ER-stress and activated the UPR and UPR-associated apoptotic cell death in vitro (63). In subcutaneous hepatocellular carcinoma (HCC) mouse models, bortezomib refocused the immune response toward tumor-associated antigens by inhibiting immune recognition of the virus. This allowed for a reduction in viral dose in the combination therapy while maintaining similar efficacy. It was further demonstrated that bortezomib's efficacy is dependent upon a functional CD8+ T-cell response, as no response was seen in vivo upon depletion of CD8+ T-cells.

\section{MITOXANTRONE}

Mitoxantrone is a type II topoisomerase inhibitor and a DNA intercalating agent. Thus, it disrupts DNA synthesis and DNA repair in both healthy cells and cancer cells (64). Mitoxantrone was initially developed for treatment of cancer and has been notably approved to treat leukemia and prostate cancer. However, due to its immunosuppressive effects, mitoxantrone was also approved for the treatment of multiple sclerosis over a decade ago. Similar to other immunosuppressive chemotherapies, its activity can be attributed to its effects on proliferating immune cells, but it also has additional effects on antigen-presenting cells and enhances suppressor T-cell functions. Mitoxantrone treatment notably reduces the secretion of pro-inflammatory cytokines such as IL-2, interferon- $\gamma($ IFN- $\gamma)$, and tumor necrosis factor alpha (65-68). This drug has been tested in combination with oncolytic HSV-1 in syngeneic murine breast tumor models (69) but only in vitro with adenovirus in prostate cancer cells (70-72). In the case of the HSV-1 ICP0 null OV KM100, mitoxantrone was found to induce immunogenic cell death and whereas no enhanced cell killing was observed in vitro, the combination treatment improved survival compared to single treatments in a Her2/neu TUBOderived syngeneic murine tumor model. This effect was associated with increased intratumoral infiltration of neutrophils and tumor antigen-specific CD8+ T-cells. It was also observed that CD8+ and CD4+ T-cells as well as Ly6G+ neutrophils were important in mediating the improved anti-tumor efficacy.

\section{IRINOTECAN}

Irinotecan or more accurately its active metabolite SN-38 inhibits topoisomerase I leading to a blockade in DNA replication and transcription. It is mainly used in colon cancer as part of a regimen known as FOLFIRI, which also includes folinic acid and 5-fluorouracil. This course of therapy has been found to reduce the number of Tregs in colorectal cancer patients with minimal impact on total lymphocyte and CD4+ T-cells counts (73). Few studies 
have used irinotecan in combination with OVs in vivo. One study showed that HSV-1 expressing CYP2B1, which converts irinotecan into $\mathrm{SN}-38$, leads to improved survival in combination with irinotecan as compared to virus or drug alone in an immunodeficient mouse glioma model (74). While potential immunological effects were not assessed, a likely contributor to the effect of combination therapy is the increased conversion of irinotecan to active $\mathrm{SN}-38$ due to the expression of CYP2B1 by the virus. Another study used oncolytic Sindbis to treat immunodeficient mice bearing human ovarian tumors (75). In this model irinotecan improved the oncolytic efficacy of Sindbis and this effect required NK cells.

\section{TEMOZOLOMIDE}

Temozolomide (TMZ) is an alkylating agent that leads to alkylation/methylation of DNA and has demonstrated clinical benefits in patients with glioblastoma (GBM) (76) and advanced metastatic melanoma (77). At higher doses, TMZ can be myeloablative and in these conditions, CD4+ and CD8+ T-cells, as well as Tregs are markedly reduced. Vaccination using an anti-tumor peptide vaccine following TMZ-induced myeloablation leads to improved CD8+ T-cell anti-tumor responses and prolongs survival in a murine model of established intracerebral tumors (78). However, Treg depletion has also been observed following lowdose TMZ in rats (79). Oncolytic adenovirus (80-83) and HSV $(84,85)$ have been tested in vivo in combination with TMZ, albeit immune effects have not been systematically explored. In one study with Ad5/3-D24-GM-CSF \pm low-dose CPA (to reduce Tregs), treatment with TMZ increased tumor cell autophagy, anti-tumor immunity, and ultimately reduced tumor burden in murine models of xenogeneic prostate cancer (82). When used in chemotherapy-refractory patients, adenovirus infusion followed by TMZ treatment was found to increase tumor-specific T-cells and immunogenic cell death as well as overall survival compared to adenovirus treatment alone.

\section{SUNITINIB}

Sunitinib is an oral, small-molecule, and multi-targeted receptor tyrosine kinase (RTK) inhibitor that was approved by the FDA for the treatment of metastatic renal cell carcinoma (RCC) and gastrointestinal stromal tumors (GIST) in 2006. Since then it has also been approved for use in neuroendocrine pancreatic cancer. Sunitinib inhibits cellular signaling by targeting multiple RTKs. These include platelet-derived growth factor receptors (PDGF-R) and vascular endothelial growth factor receptors (VEGF-R). Sunitinib also inhibits KIT (CD117), the RTK that drives the majority of GISTs. In addition, sunitinib inhibits other RTKs including RET, CSF-1R, and FLT3. Sunitinib has been recently shown to have additional off-target effects that block effector proteins of the IFN signaling pathway such as RNaseL and PKR (86).

Sunitinib has been evaluated in combination with VSV (87, 88), reovirus (87), and vaccinia virus (89). In the context of VSV oncovirotherapy, sunitinib decreased phosphorylation of the PKR substrate eIF2- $\alpha$, leading to increased viral titers in vitro. Quite remarkably, combination therapy resulted in complete and sustained tumor regression in several immunodeficient and immunocompetent mouse tumor models (88). However, sunitinib may have additional effects on the infectivity of tumor vasculature.
One study used sunitinib to transiently inhibit VEGF signaling, creating a "VEGF burst" upon treatment recovery. In combination with oncolytic VSV and reovirus, this led to increased viral infection and endothelial cell lysis as well as virus spread from blood vessels to cancerous tissues (87). A recent study looked at the combined effect of sunitinib and oncolytic vaccinia virus in syngeneic kidney and breast cancer mouse models, and found the combined treatment led to the most dramatic tumor reduction. Infection of tumors with oncolytic vaccinia as a monotherapy led to decreased VEGF expression (89), in line with the observation that vaccinia induces tumor vascular shutdown in both murine tumor models and in patients (90-92). Thereby, the combination effect in this study was attributed to enhanced tumor devascularization, although other potential effects of sunitinib on the cellular anti-viral response cannot be ruled out.

\section{DRUGS THAT EPIGENETICALLY REPROGRAM IMIMUNE RESPONSES TO ENHANCE OV THERAPY}

Epigenetic changes in gene regulation and expression can lead to phenotypic heterogeneity in genetically identical cell populations. Through reversible modifications to DNA and chromatin structures by enzymes targeting DNA, histones, and the distribution pattern of nucleosomes, the ability of transcriptional factors to access their respective promoters can be deeply altered (93). Not surprisingly, many enzymes that are involved in epigenetic regulation are deregulated in cancer and manipulation of the cancer epigenome using small molecules has been explored successfully as a treatment modality for cancer. As will be discussed in the following sub-sections, modification of the cancer epigenome has also proven beneficial to improve oncolytic virotherapy through effects on the cellular anti-viral response, the anti-tumor immune response, and even viral gene expression [for a more extensive review, refer to Ref. (1)].

\section{HDAC INHIBITORS}

Transformed cells often have defective IFN signaling pathways due to the cytokine's ability to suppress cellular proliferation and stimulate immune responses, both of which cancer cells must bypass in order to evolve to full-blown malignancies (9496). Indeed, it has been estimated that roughly three quarters of tumor cell lines within the NCI60 panel have defective IFN responses (97). Numerous reports have attributed dysfunctional IFN pathways in tumors to epigenetic silencing including DNA promoter hypermethylation and transcriptionally suppressive histone modifications [reviewed in Ref. (1)]. The extent to which interferon-stimulated genes (ISGs), the effector arsenal of the IFNmediated anti-viral response, are epigenetically silenced can lead to differences in the sensitivity to virus infection (98-102). Importantly, transcriptional activation of ISGs has been shown to require histone deacetylase (HDAC) activity (103), which has spawned the evaluation of HDAC inhibitors (HDIs) in combination with several OVs.

HDAC inhibitors including valproic acid (VPA), trichostatin A (TSA), suberoylanilide hydroxamic acid (SAHA), and MS-275 have all been used in the context of OV therapy to effectively "reprogram" IFN-responsive tumors to become permissive to OV infection. HDIs such as VPA and TSA were found to enhance 
HSV oncolysis in oral squamous carcinoma cells (SCC) (104) and glioma tumors (105-107). In one report, this was attributed to an inhibition of virally induced ISG expression, even in the presence of exogenously added IFN $\beta$ (106). The result of HDI/HSV combination therapy led to prolonged survival in several murine tumor models $(105,106)$. TSA also enhanced the oncolytic capacity of vaccinia virus, where the two agents synergistically increased cell killing in vitro in several cancer cell lines and the combination therapy led to improved survival responses in syngeneic lung metastasis and subcutaneous colorectal carcinoma mouse models (108).

Similarly, MS-275 (entinostat), SAHA (vorinostat), and other HDIs robustly sensitized resistant cells to VSV-mediated oncolysis by suppressing transcription of IFN $\beta$ and ISGs, increasing viral titers, and increasing cancer cell death. This potent synergy was cancer cell-specific and led to delayed tumor progression in xenograft models and improved viral spread within tumors in a syngeneic metastatic breast cancer model (99). While only evaluated in vitro in this study, HDI treatment of several cancer cell lines increased spreading of vaccinia and Semliki Forest viruses as well. This activity was ultimately linked to HDI-elicited dampening of the response to IFN (99).

In addition to the effects of HDIs on the response to IFN, evidence suggests HDIs can have additional immuno-modulatory properties. Particularly striking effects of HDIs have been observed in the context of a heterologous oncolytic prime-boost strategy, where mice with syngeneic B16 melanoma brain tumors were first primed with an oncolytic adenovirus expressing the tumor-associated antigen dopachrome tautomerase (hDCT, overexpressed in B16) then treated with oncolytic VSV expressing hDCT. MS-275 given along with VSV-hDCT potentiated the antitumor response to hDCT while suppressing the adaptive anti-viral response, ultimately redirecting the immune response toward the tumor. As a result, efficacy was dramatically improved, where the majority of mice given MS-275 in the prime-boost regime experienced long-lasting ( $>200$ day) cures, compared to $100 \%$ mortality before day 50 in the mice given the same therapy minus MS-275 (109). In this study, it was also shown that MS-275 reduced virus neutralizing antibodies and memory CD8+ T-cells while maintaining prime-induced levels of humoral and cellular immunity against the tumor antigen (109).

\section{5-AZA}

DNA methylation and histone modifications are highly interdependent epigenetic processes (110). In addition to histone acetylation-mediated gene silencing, ISGs and other genes implicit in the IFN-mediated anti-viral response are often silenced in cancers by DNA hypermethylation at CpG islands in their promoter region [reviewed in Ref. (1)]. In addition to cellular genes, viral genomes can also be susceptible to direct epigenetic silencing. For example, oncolytic HSV rQNestin34.5 is transcriptionally silenced upon infection of glioma cells, due to increased DNA methylation levels at the virally encoded mammalian Nestin promoter (111). As such, some groups have investigated using OVs in combination with 5-AZA-2'-deoxycytidine (5-AZA): a DNA methyltransferase inhibitor that prevents DNA methylation and allows silenced DNA to regain accessibility to transcription factors. In the case of oncolytic HSV rQNestin34.5, treatment with
5-AZA was sufficient to de-repress transcription under control of the Nestin promoter, allowing viral gene expression, increased viral replication, and HSV-mediated glioma cell killing. This translated to increased survival in glioma bearing mice treated with both 5-AZA and the OV, compared to either treatment administered alone (111). However, it is interesting to mention that in the same study, VPA an HDAC inhibitor was sufficient to drive down DNA methylation at the Nestin promoter in vitro in infected glioma cells, highlighting the closely interrelated impact of DNA methylation and histone modification (111).

\section{PI3K/Akt/mTOR PATHWAY INHIBITORS}

The phosphoinositide 3-kinase (PI3K) pathway is critical to cell survival/apoptosis signaling in response to stress. Genetic mutations in the P13K pathway frequently occur in cancers resulting in dysfunctional apoptotic responses and pro-survival signaling (112). Various growth hormones and stress signals including IFN$\alpha$ activate PI3K, which triggers a signaling cascade leading to Akt phosphorylation $(112,113)$. This activates the kinase, which then phosphorylates a number of cellular factors involved in cell survival and proliferation such as NF- $\mathrm{B}$, which is also involved in inducing the type I IFN cascade.

Several PI3K pathway inhibitors including GDC-0941 and NVP-BEZ235 are currently being clinically evaluated for the treatment of cancer (114). Both GDC-0941 and LY294002, a common PI3K inhibitor chemical probe, inhibit PI3K activity via competitive inhibition of an ATP binding site on the p85 $\alpha$ subunit (115). The PI3K inhibitors LY294002, GDC-0941, BEZ235, as well as the Akt inhibitor tricibine, acted synergistically with oncolytic HSV MG18L to induce apoptosis in glioma cell lines in vitro in a cancer cell-specific manner. Remarkably, combination therapy resulted in durable cures in mice bearing glioblastoma multiforme (GBM) tumors, surpassing the efficacy of either therapy administered alone (116). Recent findings also indicated LY294002 increased killing of multiple myeloma cells in vitro triggered by the oncolytic adenovirus ZD55-TRAIL (117).

Mammalian target of rapamycin (mTOR), a master regulator of cellular translation, is downstream of PI3K and Akt signaling. Indeed, both GDC-0941 and NVP-BEZ235, a PI3K inhibitor developed by Novartis, have been reported to inhibit mTOR as well as PI3K (114). While mTOR controls translation of a host of cellular mRNAs and can also impact translation of viral proteins, evidence suggests it can control the anti-viral response by regulating translation of IFN and other key mediators of the anti-viral response such as IRF-7 (118). The mTOR inhibitor rapamycin, a well-known immunosuppressant, has been tested in combination with several OVs including oncolytic adenovirus $(119,120)$, HSV (121), VSV (122), and myxoma $(123,124)$. Treatment with rapamycin or closely related mTOR inhibitors such as everolimus (RAD001) has been reported to suppress the adaptive immune response to OVs by reducing levels of antibodies generated against the viruses (120), improving OV activity in several rodent models of cancer (119-121). In one study, enhancement of OV activity was also observed in vitro following treatment with rapamycin (121). This may be due to the impact of rapamycin on the IFN response as determined from another study where rapamycin was shown to reduce levels of VSV-induced IFN in rats, improving VSV efficacy 
in an aggressive rat glioma model (122). Interestingly, oncolytic myxoma is enhanced by rapamycin in normally resistant human tumor cells in vitro; however, the mechanism by which this occurs is thought to be due to rapamycin-induced increases in Akt kinase levels optimal for sustaining myxoma replication (123).

\section{OTHER PROMISING IMMUNO-MODULATORY OV-ENHANCING DRUGS \\ NOVEL VIRAL SENSITIZERS}

The paragraphs above have shown countless examples of empirically or rationally selected combination therapeutic approaches aiming to improve the activity of OVs using well-characterized chemotherapeutics and signaling pathway inhibitors. A highthroughput screen was performed in an effort to expand this approach in an unbiased manner to identify previously uncharacterized small molecules that enhance OV activity. This screen was performed using oncolytic VSV $\Delta$ M51 in the resistant murine breast cancer cell line 4T1 (125). Several molecules were identified as novel "viral sensitizers" (VSes) that were capable of boosting VSV replication and spread in vitro. One of these compounds, VSe1, boosted VSV $\Delta$ M51 replication by up to 1000 -fold, and was found to synergistically increase tumor cell killing. The mode of action of VSel is not fully understood but at a minimum it involves disruption of the IFN response. More specifically, ISGs typically triggered upon VSV infection remained silenced in cells pre-treated with VSe1 (125). When used as a combination therapy to treat an aggressive mouse colon carcinoma model refractory to VSV $\Delta \mathrm{M} 51, \mathrm{VSe} 1$ potentiated OV activity leading to delayed tumor progression in the context of the combination treatment, while either VSV $\Delta$ M51 or VSel alone had no appreciable anti-cancer effects (125).

\section{TRIPTOLIDE}

Triptolide (TPL) is a naturally derived component of the Chinese herb Tripterygium wilfordii and has been used for centuries as an anti-inflammatory remedy that has also been found to have anti-cancer properties (126-128). TPL is known to be a global transcription inhibitor and has multiple effects including the inhibition of RNA polymerase II and the expression of genes involved in apoptosis and NFKB signaling (129). A recent report found that TPL also suppresses IFN signaling downstream of IRF3 (130). When combined with oncolytic VSV both in vitro in VSV-resistant tumor cells and in vivo in an aggressive mouse GBM tumor model, the two therapies synergistically improved tumor-specific virus replication leading prolonged survival and delayed tumor progression compared to either therapy given alone (130).

\section{JAK KINASE INHIBITORS}

Ruxolitinib (Jakafi) is a Jak1/2 kinase inhibitor (131) approved in 2011 for the treatment of myelofibrosis (132). Patients with myeloproliferative neoplasms often possess an activating mutation in the gene encoding Jak2 (133), resulting in aberrant inflammatory cytokine release and splenomegaly. Treatment with ruxolitinib, while not targeting the genetic determinant of the neoplasm, led to profound resolution of severe symptoms in human trials to treat myelofibrosis (splenomegaly, weight loss, fatigue), and this clinical efficacy was associated with a potent reduction in inflammatory cytokine levels (134). Given that Jak1 is required for type
I IFN signaling and induction of ISGs, Jak1 inhibitors have the potential to benefit OV therapy in IFN-responsive tumors. Both ruxolitinib and Jak inhibitor 1 were sufficient to sensitize VSVresistant squamous cell carcinoma cells in vitro to VSV infection, and this sensitization was associated with marked decreases in ISG expression (135). Pre-treatment with the Jak inhibitor 1 also sensitized sarcoma and bladder carcinoma cells to VSV infection in vitro (136).

\section{CHECKPOINT INHIBITORS}

Targeting T-cell inhibitory check point molecules, including the Tcell inhibitory receptor cytotoxic T-lymphocyte antigen 4 (CTLA4) and programed cell death 1 (PD1), is a relatively new therapeutic approach to cancer therapy. During normal immune responses, T-cell checkpoint receptors such as PD1 and CTLA-4 prevent overactive T-cell responses, which can lead to harmful tissue damage. However in cancers, tumor infiltrating T-cells are often inhibited by both PD1 and CTLA- 4 stimulation. As a result, T-cell anergy is a major barrier to immune-mediated tumor recognition and clearance. Given the ability of OVs to stimulate an anti-tumor immune response, combining OV with checkpoint inhibitors has emerged as a logical combination approach. While several groups are currently working on this approach, published studies to date have focused on ipilimumab, an anti-CTLA- 4 antibody approved to treat melanoma in 2011. By targeting CTLA-4, ipilimumab blocks interaction with its ligands, CD80/CD86, leading to increases in Tcell mediated anti-tumor responses. Anti-CTLA-4 antibodies have been used in combination with oncolytic parvovirus in vitro (137) and Newcastle disease virus (NDV) in vivo to treat murine B16 melanoma (138). Remarkably, the combination therapy of NDV and anti-CTLA-4 led to nearly $70 \%$ cures in a B16 melanoma mouse model compared to $20 \%$ cures for anti-CTLA- 4 antibody alone and no effect of the OV on its own (138). Notably, NDV complemented with anti-CTLA-4 led to an increase in the infiltration of activated CD8+ and CD4+ T-cells and a reduction in Tregs.

\section{CONCLUSION}

Successful therapy using OVs will ultimately depend on effectively navigating the delicate balance between the anti-viral response and the anti-tumor immune response such as to minimize the former in the short term and maximize the latter in the long term. As outlined above, several approved drugs and novel small molecules can be effective tools to dampen the innate and adaptive anti-viral responses, increase the anti-tumor immune response, or both. However, given the close interplay between the cellular antiviral response and the adaptive immune response that is required for prolonged tumor control, OV/drug scheduling is likely to be critical. To this end, it is probable that the combination of some of the agents described above may allow for additional flexibility and more effective therapy. For example, one can easily foresee first using a drug that specifically dampens the cellular antiviral to permit robust OV replication followed with another that promotes the generation of an anti-tumor response. However, given the efficacy of each approach is undoubtedly both context-dependent (e.g., tumor type and tumor site) and OV-dependent, more preclinical and clinical studies will be necessary to identify winning 
combinations that can maximize the potential for curing cancers in a clinical context.

While many studies demonstrate therapeutic benefit of combination therapies at least in animal models, we can perceive a deficit in regards to systematic head-to-head comparisons of different combination therapies coupling OVs and the immunemodulatory drugs reviewed above. While such a feat may prove daunting experimentally, this exercise seems warranted and necessary to delineate a more educated choice of combination therapies to push forward into clinical trials. One clear trend overall is that evaluation of promising combination therapies with novel immuno-modulatory agents seems to stop at the pre-clinical level. There are likely several factors that contribute to this. For example, companies developing novel small molecules may be reluctant to explore combinations with OVs that are still relatively novel themselves. Similarly, novel small molecules need to be validated clinically, which complicates clinical trial design and adds additional risk from the perspective of those spearheading clinical translation of OVs. This is particularly challenging for novel small molecules such as VSe1, which have been selected for the sole purpose of enhancing OV activity (125). This type of smallmolecule/OV co-development can only be reasonably achieved by pharmaceutical companies that have experience in developing both small-molecule and biological therapies separately. Hence, from a clinical perspective, it is likely that the combination of $\mathrm{OV}$ therapy with a chemotherapy drug that is part of current standard of care would be the easiest to implement as demonstrated with the combination of oncolytic adenovirus and CPA (27). With promising results emerging from the clinic showing benefits combining OVs with traditional chemotherapy drugs, and as pharmaceutical companies such as Amgen begin to take heed of the potential of OV therapy for the treatment of cancer, clinical evaluation of some of the more novel OV-synergizing compounds seems likely in the near future as a means to overcome heterogeneity in clinical response.

\section{ACKNOWLEDGMENTS}

This work was supported by grants from the Terry Fox Research Institute (grant \# TFF 122868) and The Lotte and John Hecht Memorial Foundation Innovation Grant of the Canadian Cancer Society (grant \#2012-701460) held by Jean-Simon Diallo.

\section{REFERENCES}

1. Forbes NE, Abdelbary H, Lupien M, Bell JC, Diallo JS. Exploiting tumor epigenetics to improve oncolytic virotherapy. Front Genet (2013) 4:184. doi:10.3389/fgene.2013.00184

2. Ilkow CS, Swift SL, Bell JC, Diallo JS. From scourge to cure: tumour-selective viral pathogenesis as a new strategy against cancer. PLoS Pathog (2014) 10:e1003836. doi:10.1371/journal.ppat.1003836

3. Prestwich RJ, Errington F, Ilett EJ, Morgan RS, Scott KJ, Kottke T, et al. Tumor infection by oncolytic reovirus primes adaptive antitumor immunity. Clin Cancer Res (2008) 14:7358-66. doi:10.1158/1078-0432.CCR-08-0831

4. Gujar SA, Pan DA, Marcato P, Garant KA, Lee PW. Oncolytic virus-initiated protective immunity against prostate cancer. Mol Ther (2011) 19:797-804. doi:10.1038/mt.2010.297

5. Steele L, Errington F, Prestwich R, Ilett E, Harrington K, Pandha H, et al. Proinflammatory cytokine/chemokine production by reovirus treated melanoma cells is PKR/NF-kappaB mediated and supports innate and adaptive antitumour immune priming. Mol Cancer (2011) 10:20. doi:10.1186/1476-4598$10-20$
6. Russell SJ, Peng KW, Bell JC. Oncolytic virotherapy. Nat Biotechnol (2012) 30:658-70. doi:10.1038/nbt.2287

7. Park BH, Hwang T, Liu TC, Sze DY, Kim JS, Kwon HC, et al. Use of a targeted oncolytic poxvirus, JX-594, in patients with refractory primary or metastatic liver cancer: a phase I trial. Lancet Oncol (2008) 9:533-42. doi:10.1016/S1470-2045(08)70107-4

8. Galanis E, Markovic SN, Suman VJ, Nuovo GJ, Vile RG, Kottke TJ, et al. Phase II trial of intravenous administration of Reolysin((R)) (Reovirus Serotype3-dearing Strain) in patients with metastatic melanoma. Mol Ther (2012) 20:1998-2003. doi:10.1038/mt.2012.146

9. Kim KH, Dmitriev IP, Saddekni S, Kashentseva EA, Harris RD, Aurigemma $\mathrm{R}$, et al. A phase I clinical trial of Ad5/3-Delta24, a novel serotype-chimeric, infectivity-enhanced, conditionally-replicative adenovirus (CRAd), in patients with recurrent ovarian cancer. Gynecol Oncol (2013) 130:518-24. doi:10.1016/ j.ygyno.2013.06.003

10. Morris DG, Feng X, Difrancesco LM, Fonseca K, Forsyth PA, Paterson AH, et al. REO-001: a phase I trial of percutaneous intralesional administration of reovirus type 3 dearing (Reolysin(R)) in patients with advanced solid tumors. Invest New Drugs (2013) 31:696-706. doi:10.1007/s10637-012-9865-z

11. Garber K. China approves world's first oncolytic virus therapy for cancer treatment. J Natl Cancer Inst (2006) 98:298-300. doi:10.1093/jnci/djj111

12. Andtbacka RH, Collichio FA, Amatruda T, Senzer NN, Chesney J, Delman KA, et al. OPTiM: a randomized phase III trial of talimogene laherparepvec (TVEC) versus subcutaneous (SC) granulocyte-macrophage colony-stimulating factor (GM-CSF) for the treatment (tx) of unresected stage IIIB/C and IV melanoma. J Clin Oncol (2013) 31:LBA9008.

13. Helfand C. Amgen to Pursue T-Vec Approval Despite PhIII Survival Miss [Online]. FierceMarkets. (2014) [cited 2014 Jun 24]. Available from: http:// www.fiercevaccines.com/story/amgen-pursue-t-vec-approval-despite-phiiisurvival-miss/2014-06-03?utm_medium=nl\&utm_source=internal

14. Senzer NN, Kaufman HL, Amatruda T, Nemunaitis M, Reid T, Daniels G, et al. Phase II clinical trial of a granulocyte-macrophage colony-stimulating factor-encoding, second-generation oncolytic herpesvirus in patients with unresectable metastatic melanoma. J Clin Oncol (2009) 27:5763-71. doi:10. 1200/JCO.2009.24.3675

15. Breitbach CJ, Burke J, Jonker D, Stephenson J, Haas AR, Chow LQ, et al. Intravenous delivery of a multi-mechanistic cancer-targeted oncolytic poxvirus in humans. Nature (2011) 477:99-102. doi:10.1038/nature10358

16. Heo J, Reid T, Ruo L, Breitbach CJ, Rose S, Bloomston M, et al. Randomized dose-finding clinical trial of oncolytic immunotherapeutic vaccinia JX-594 in liver cancer. Nat Med (2013) 19:329-36. doi:10.1038/nm.3089

17. Ottolino-Perry K, Diallo JS, Lichty BD, Bell JC, Andrea Mccart J. Intelligent design: combination therapy with oncolytic viruses. Mol Ther (2010) 18:251-63. doi:10.1038/mt.2009.283

18. Hanahan D, Weinberg RA. Hallmarks of cancer: the next generation. Cell (2011) 144:646-74. doi:10.1016/j.cell.2011.02.013

19. Emadi A, Jones RJ, Brodsky RA. Cyclophosphamide and cancer: golden anniversary. Nat Rev Clin Oncol (2009) 6:638-47. doi:10.1038/nrclinonc.2009. 146

20. Ikeda K, Ichikawa T, Wakimoto H, Silver JS, Deisboeck TS, Finkelstein D, et al. Oncolytic virus therapy of multiple tumors in the brain requires suppression of innate and elicited antiviral responses. Nat Med (1999) 5:881-7. doi:10.1038/11320

21. Ikeda K, Wakimoto H, Ichikawa T, Jhung S, Hochberg FH, Louis DN, et al. Complement depletion facilitates the infection of multiple brain tumors by an intravascular, replication-conditional herpes simplex virus mutant. J Virol (2000) 74:4765-75. doi:10.1128/JVI.74.10.4765-4775.2000

22. Wakimoto H, Fulci G, Tyminski E, Chiocca EA. Altered expression of antiviral cytokine mRNAs associated with cyclophosphamide's enhancement of viral oncolysis. Gene Ther (2004) 11:214-23. doi:10.1038/sj.gt.3302143

23. Fulci G, Breymann L, Gianni D, Kurozomi K, Rhee SS, Yu J, et al. Cyclophosphamide enhances glioma virotherapy by inhibiting innate immune responses. Proc Natl Acad Sci U S A (2006) 103:12873-8. doi:10.1073/pnas.0605496103

24. Currier MA, Gillespie RA, Sawtell NM, Mahller YY, Stroup G, Collins MH, et al. Efficacy and safety of the oncolytic herpes simplex virus rRp450 alone and combined with cyclophosphamide. Mol Ther (2008) 16:879-85. doi: $10.1038 / \mathrm{mt} .2008 .49$

25. Thomas MA, Spencer JF, Toth K, Sagartz JE, Phillips NJ, Wold WS. Immunosuppression enhances oncolytic adenovirus replication and antitumor efficacy 
in the Syrian hamster model. Mol Ther (2008) 16:1665-73. doi:10.1038/mt. 2008.162

26. Dhar D, Spencer JF, Toth K, Wold WS. Effect of preexisting immunity on oncolytic adenovirus vector INGN 007 antitumor efficacy in immunocompetent and immunosuppressed Syrian hamsters. J Virol (2009) 83:2130-9. doi:10.1128/JVI.02127-08

27. Cerullo V, Diaconu I, Kangasniemi L, Rajecki M, Escutenaire S, Koski A, et al. Immunological effects of low-dose cyclophosphamide in cancer patients treated with oncolytic adenovirus. Mol Ther (2011) 19:1737-46. doi:10.1038/ mt.2011.113

28. Hasegawa N, Abei M, Yokoyama KK, Fukuda K, Seo E, Kawashima R, et al. Cyclophosphamide enhances antitumor efficacy of oncolytic adenovirus expressing uracil phosphoribosyltransferase (UPRT) in immunocompetent Syrian hamsters. Int J Cancer (2013) 133:1479-88. doi:10.1002/ijc.28132

29. Lun XQ, Jang JH, Tang N, Deng H, Head R, Bell JC, et al. Efficacy of systemically administered oncolytic vaccinia virotherapy for malignant gliomas is enhanced by combination therapy with rapamycin or cyclophosphamide. Clin Cancer Res (2009) 15:2777-88. doi:10.1158/1078-0432.CCR-08-2342

30. Qiao J, Wang H, Kottke T, White C, Twigger K, Diaz RM, et al. Cyclophosphamide facilitates antitumor efficacy against subcutaneous tumors following intravenous delivery of reovirus. Clin Cancer Res (2008) 14:259-69. doi:10.1158/1078-0432.CCR-07-1510

31. Ungerechts G, Springfeld C, Frenzke ME, Lampe J, Parker WB, Sorscher EJ, et al. An immunocompetent murine model for oncolysis with an armed and targeted measles virus. Mol Ther (2007) 15:1991-7. doi:10.1038/sj.mt.6300291

32. Ungerechts G, Frenzke ME, Yaiw KC, Miest T, Johnston PB, Cattaneo R. Mantle cell lymphoma salvage regimen: synergy between a reprogrammed oncolytic virus and two chemotherapeutics. Gene Ther (2010) 17:1506-16. doi:10.1038/gt.2010.103

33. Peng KW, Myers R, Greenslade A, Mader E, Greiner S, Federspiel MJ, et al. Using clinically approved cyclophosphamide regimens to control the humoral immune response to oncolytic viruses. Gene Ther (2013) 20:255-61. doi:10.1038/gt.2012.31

34. Kottke T, Thompson J, Diaz RM, Pulido J, Willmon C, Coffey M, et al. Improved systemic delivery of oncolytic reovirus to established tumors using preconditioning with cyclophosphamide-mediated Treg modulation and interleukin-2. Clin Cancer Res (2009) 15:561-9. doi:10.1158/1078-0432.CCR-08-1688

35. Mini E, Nobili S, Caciagli B, Landini I, Mazzei T. Cellular pharmacology of gemcitabine. Ann Oncol (2006) 17(Suppl 5):v7-12. doi:10.1093/annonc/mdj941

36. Lolkema MP, Arkenau HT, Harrington K, Roxburgh P, Morrison R, Roulstone $\mathrm{V}$, et al. A phase I study of the combination of intravenous reovirus type 3 Dearing and gemcitabine in patients with advanced cancer. Clin Cancer Res (2011) 17:581-8. doi:10.1158/1078-0432.CCR-10-2159

37. Gabrilovich DI, Nagaraj S. Myeloid-derived suppressor cells as regulators of the immune system. Nat Rev Immunol (2009) 9:162-74. doi:10.1038/nri2506

38. Leitner S, Sweeney K, Oberg D, Davies D, Miranda E, Lemoine NR, et al. Oncolytic adenoviral mutants with E1B19K gene deletions enhance gemcitabine-induced apoptosis in pancreatic carcinoma cells and anti-tumor efficacy in vivo. Clin Cancer Res (2009) 15:1730-40. doi:10.1158/1078-0432. CCR-08-2008

39. Liu D, Kojima T, Ouchi M, Kuroda S, Watanabe Y, Hashimoto Y, et al. Preclinical evaluation of synergistic effect of telomerase-specific oncolytic virotherapy and gemcitabine for human lung cancer. Mol Cancer Ther (2009) 8:980-7. doi:10.1158/1535-7163.MCT-08-0901

40. Onimaru M, Ohuchida K, Nagai E, Mizumoto K, Egami T, Cui L, et al. Combination with low-dose gemcitabine and hTERT-promoter-dependent conditionally replicative adenovirus enhances cytotoxicity through their crosstalk mechanisms in pancreatic cancer. Cancer Lett (2010) 294:178-86. doi:10.1016/ j.canlet.2010.01.034

41. Bhattacharyya M, Francis J, Eddouadi A, Lemoine NR, Hallden G. An oncolytic adenovirus defective in pRb-binding (dl922-947) can efficiently eliminate pancreatic cancer cells and tumors in vivo in combination with 5-FU or gemcitabine. Cancer Gene Ther (2011) 18:734-43. doi:10.1038/cgt.2011.45

42. Cherubini G, Kallin C, Mozetic A, Hammaren-Busch K, Muller H, Lemoine $\mathrm{NR}$, et al. The oncolytic adenovirus Ad $\delta \delta$ enhances selective cancer cell killing in combination with DNA-damaging drugs in pancreatic cancer models. Gene Ther (2011) 18:1157-65. doi:10.1038/gt.2011.141
43. Wang H, Satoh M, Chen GP, Li DC, Hamada H, Arai Y. E1A, E1B doublerestricted adenovirus enhances the cytotoxicity and antitumor activity of gemcitabine to renal cell carcinoma. Chin Med J (Engl) (2011) 124:1082-7.

44. Kangasniemi L, Parviainen S, Pisto T, Koskinen M, Jokinen M, Kiviluoto T, et al. Effects of capsid-modified oncolytic adenoviruses and their combinations with gemcitabine or silica gel on pancreatic cancer. Int J Cancer (2012) 131:253-63. doi:10.1002/ijc. 26370

45. Angelova AL, Aprahamian M, Grekova SP, Hajri A, Leuchs B, Giese NA, et al. Improvement of gemcitabine-based therapy of pancreatic carcinoma by means of oncolytic parvovirus H-1PV. Clin Cancer Res (2009) 15:511-9. doi:10.1158/1078-0432.CCR-08-1088

46. Angelova AL, Grekova SP, Heller A, Kuhlmann O, Soyka E, Giese T, et al. Complementary induction of immunogenic cell death by oncolytic parvovirus $\mathrm{H}-1 \mathrm{PV}$ and gemcitabine in pancreatic cancer. J Virol (2014) 88:5263-76. doi:10.1128/JVI.03688-13

47. Sei S, Mussio JK, Yang QE, Nagashima K, Parchment RE, Coffey MC, et al. Synergistic antitumor activity of oncolytic reovirus and chemotherapeutic agents in non-small cell lung cancer cells. Mol Cancer (2009) 8:47. doi:10.1186/1476-4598-8-47

48. Gujar SA, Clements D, Dielschneider R, Helson E, Marcato P, Lee PW. Gemcitabine enhances the efficacy of reovirus-based oncotherapy through anti-tumour immunological mechanisms. Br J Cancer (2014) 110:83-93. doi:10.1038/bjc.2013.695

49. Hastie E, Besmer DM, Shah NR, Murphy AM, Moerdyk-Schauwecker M, Molestina C, et al. Oncolytic vesicular stomatitis virus in an immunocompetent model of MUC1-positive or MUC1-null pancreatic ductal adenocarcinoma. J Virol (2013) 87:10283-94. doi:10.1128/JVI.01412-13

50. Watanabe I, Kasuya H, Nomura N, Shikano T, Shirota T, Kanazumi N, et al. Effects of tumor selective replication-competent herpes viruses in combination with gemcitabine on pancreatic cancer. Cancer Chemother Pharmacol (2008) 61:875-82. doi:10.1007/s00280-007-0567-8

51. Esaki S, Goshima F, Kimura H, Murakami S, Nishiyama Y. Enhanced antitumoral activity of oncolytic herpes simplex virus with gemcitabine using colorectal tumor models. Int J Cancer (2013) 132:1592-601. doi:10.1002/ijc.27823

52. Yu YA, Galanis C, Woo Y, Chen N, Zhang Q, Fong Y, et al. Regression of human pancreatic tumor xenografts in mice after a single systemic injection of recombinant vaccinia virus GLV-1h68. Mol Cancer Ther (2009) 8:141-51. doi:10.1158/1535-7163.MCT-08-0533

53. Wennier ST, Liu J, Li S, Rahman MM, Mona M, Mcfadden G. Myxoma virus sensitizes cancer cells to gemcitabine and is an effective oncolytic virotherapeutic in models of disseminated pancreatic cancer. Mol Ther (2012) 20:759-68. doi:10.1038/mt.2011.293

54. Bonvini P, Zorzi E, Basso G, Rosolen A. Bortezomib-mediated 26S proteasome inhibition causes cell-cycle arrest and induces apoptosis in CD-30+ anaplastic large cell lymphoma. Leukemia (2007) 21:838-42. doi:10.1038/sj.leu.2404528

55. Berenson JR, Ma HM, Vescio R. The role of nuclear factor-kappaB in the biology and treatment of multiple myeloma. Semin Oncol (2001) 28:626-33. doi:10.1053/sonc.2001.29542

56. Diallo JS, Betton B, Parent N, Peant B, Lessard L, Le Page C, et al. Enhanced killing of androgen-independent prostate cancer cells using inositol hexakisphosphate in combination with proteasome inhibitors. Br J Cancer (2008) 99:1613-22. doi:10.1038/sj.bjc.6604730

57. Nawrocki ST, Carew JS, Dunner K Jr., Boise LH, Chiao PJ, Huang P, et al. Bortezomib inhibits PKR-like endoplasmic reticulum (ER) kinase and induces apoptosis via ER stress in human pancreatic cancer cells. Cancer Res (2005) 65:11510-9. doi:10.1158/0008-5472.CAN-05-2370

58. Marshansky V, Wang X, Bertrand R, Luo H, Duguid W, Chinnadurai G, et al. Proteasomes modulate balance among proapoptotic and antiapoptotic Bcl-2 family members and compromise functioning of the electron transport chain in leukemic cells. J Immunol (2001) 166:3130-42. doi:10.4049/jimmunol.166. 5.3130

59. Chang CL, Hsu YT, Wu CC, Yang YC, Wang C, Wu TC, et al. Immune mechanism of the antitumor effects generated by bortezomib. J Immunol (2012) 189:3209-20. doi:10.4049/jimmunol.1103826

60. Berges C, Haberstock H, Fuchs D, Miltz M, Sadeghi M, Opelz G, et al. Proteasome inhibition suppresses essential immune functions of human CD4+ T cells. Immunology (2008) 124:234-46. doi:10.1111/j.1365-2567.2007.02761.x 
61. Yarde DN, Nace RA, Russell SJ. Oncolytic vesicular stomatitis virus and bortezomib are antagonistic against myeloma cells in vitro but have additive antimyeloma activity in vivo. Exp Hematol (2013) 41:1038-49. doi:10.1016/j. exphem.2013.09.005

62. Carew JS, Espitia CM, Zhao W, Kelly KR, Coffey M, Freeman JW, et al. Reolysin is a novel reovirus-based agent that induces endoplasmic reticular stress-mediated apoptosis in pancreatic cancer. Cell Death Dis (2013) 4:e728. doi:10.1038/cddis.2013.259

63. Boozari B, Mundt B, Woller N, Struver N, Gurlevik E, Schache P, et al. Antitumoural immunity by virus-mediated immunogenic apoptosis inhibits metastatic growth of hepatocellular carcinoma. Gut (2010) 59:1416-26. doi:10.1136/ gut.2009.196519

64. Mazerski J, Martelli S, Borowski E. The geometry of intercalation complex of antitumor mitoxantrone and ametantrone with DNA: molecular dynamics simulations. Acta Biochim Pol (1998) 45:1-11.

65. Fidler JM, Dejoy SQ, Smith FR III, Gibbons JJ Jr. Selective immunomodulation by the antineoplastic agent mitoxantrone. II. Nonspecific adherent suppressor cells derived from mitoxantrone-treated mice. J Immunol (1986) 136:2747-54.

66. Neuhaus O, Wiendl H, Kieseier BC, Archelos JJ, Hemmer B, Stuve O, et al. Multiple sclerosis: mitoxantrone promotes differential effects on immunocompetent cells in vitro. J Neuroimmunol (2005) 168:128-37. doi:10.1016/j.jneuroim. 2005.01.024

67. Kopadze T, Dehmel T, Hartung HP, Stuve O, Kieseier BC. Inhibition by mitoxantrone of in vitro migration of immunocompetent cells: a possible mechanism for therapeutic efficacy in the treatment of multiple sclerosis. Arch Neurol (2006) 63:1572-8. doi:10.1001/archneur.63.11.1572

68. Okuda DT. Immunosuppressive treatments in multiple sclerosis. Handb Clin Neurol (2014) 122:503-11. doi:10.1016/B978-0-444-52001-2.00022-4

69. Workenhe S, Pol JG, Lichty BD, Cummings DT, Mossman KL. Combining oncolytic HSV-1 with immunogenic cell death-inducing drug mitoxantrone breaks cancer immune tolerance and improves therapeutic efficacy. Cancer Immunol Res (2013) 1:1-11. doi:10.1158/2326-6066.CIR-13-0059-T

70. Oberg D, Yanover E, Adam V, Sweeney K, Costas C, Lemoine NR, et al. Improved potency and selectivity of an oncolytic E1ACR2 and E1B19K deleted adenoviral mutant in prostate and pancreatic cancers. Clin Cancer Res (2010) 16:541-53. doi:10.1158/1078-0432.CCR-09-1960

71. Radhakrishnan S, Miranda E, Ekblad M, Holford A, Pizarro MT, Lemoine $\mathrm{NR}$, et al. Efficacy of oncolytic mutants targeting pRb and p53 pathways is synergistically enhanced when combined with cytotoxic drugs in prostate cancer cells and tumor xenografts. Hum Gene Ther (2010) 21:1311-25. doi:10.1089/hum.2010.019

72. Miranda E, Maya Pineda H, Oberg D, Cherubini G, Garate Z, Lemoine NR, et al. Adenovirus-mediated sensitization to the cytotoxic drugs docetaxel and mitoxantrone is dependent on regulatory domains in the E1ACR1 gene-region. PLoS One (2012) 7:e46617. doi:10.1371/journal.pone.0046617

73. Maeda K, Hazama S, Tokuno K, Kan S, Maeda Y, Watanabe Y, et al. Impact of chemotherapy for colorectal cancer on regulatory T-cells and tumor immunity. Anticancer Res (2011) 31:4569-74.

74. Tyminski E, Leroy S, Terada K, Finkelstein DM, Hyatt JL, Danks MK, et al. Brain tumor oncolysis with replication-conditional herpes simplex virus type 1 expressing the prodrug-activating genes, CYP2B1 and secreted human intestinal carboxylesterase, in combination with cyclophosphamide and irinotecan. Cancer Res (2005) 65:6850-7. doi:10.1158/0008-5472.CAN-05-0154

75. Granot T, Meruelo D. The role of natural killer cells in combinatorial anticancer therapy using Sindbis viral vectors and irinotecan. Cancer Gene Ther (2012) 19:588-91. doi:10.1038/cgt.2012.33

76. Stupp R, Mason WP, Van Den Bent MJ, Weller M, Fisher B, Taphoorn MJ, et al. Radiotherapy plus concomitant and adjuvant temozolomide for glioblastoma. N Engl J Med (2005) 352:987-96. doi:10.1056/NEJMoa043330

77. Middleton MR, Grob JJ, Aaronson N, Fierlbeck G, Tilgen W, Seiter S, et al. Randomized phase III study of temozolomide versus dacarbazine in the treatment of patients with advanced metastatic malignant melanoma. J Clin Oncol (2000) 18:158-66.

78. Sanchez-Perez LA, Choi BD, Archer GE, Cui X, Flores C, Johnson LA, et al. Myeloablative temozolomide enhances CD8(+) T-cell responses to vaccine and is required for efficacy against brain tumors in mice. PLoS One (2013) 8:e59082. doi:10.1371/journal.pone.0059082
79. Banissi C, Ghiringhelli F, Chen L, Carpentier AF. Treg depletion with a low-dose metronomic temozolomide regimen in a rat glioma model. Cancer Immunol Immunother (2009) 58:1627-34. doi:10.1007/s00262-009-0671-1

80. Alonso MM, Gomez-Manzano C, Jiang H, Bekele NB, Piao Y, Yung WK, et al. Combination of the oncolytic adenovirus ICOVIR- 5 with chemotherapy provides enhanced anti-glioma effect in vivo. Cancer Gene Ther (2007) 14:756-61. doi:10.1038/sj.cgt.7701067

81. Holzmuller R, Mantwill K, Haczek C, Rognoni E, Anton M, Kasajima A, et al. YB-1 dependent virotherapy in combination with temozolomide as a multimodal therapy approach to eradicate malignant glioma. Int J Cancer (2011) 129:1265-76. doi:10.1002/ijc. 25783

82. Liikanen I, Ahtiainen L, Hirvinen ML, Bramante S, Cerullo V, Nokisalmi P, et al. Oncolytic adenovirus with temozolomide induces autophagy and antitumor immune responses in cancer patients. Mol Ther (2013) 21:1212-23. doi: $10.1038 / \mathrm{mt} .2013 .51$

83. Tobias AL, Thaci B, Auffinger B, Rincon E, Balyasnikova IV, Kim CK, et al. The timing of neural stem cell-based virotherapy is critical for optimal therapeutic efficacy when applied with radiation and chemotherapy for the treatment of glioblastoma. Stem Cells Transl Med (2013) 2:655-66. doi:10.5966/sctm.20130039

84. Aghi M, Rabkin S, Martuza RL. Effect of chemotherapy-induced DNA repair on oncolytic herpes simplex viral replication. J Natl Cancer Inst (2006) 98:38-50. doi:10.1093/jnci/djj003

85. Kanai R, Rabkin SD, Yip S, Sgubin D, Zaupa CM, Hirose Y, et al. Oncolytic virusmediated manipulation of DNA damage responses: synergy with chemotherapy in killing glioblastoma stem cells. J Natl Cancer Inst (2012) 104:42-55. doi:10.1093/jnci/djr509

86. Jha BK, Polyakova I, Kessler P, Dong B, Dickerman B, Sen GC, et al. Inhibition of RNase L and RNA-dependent protein kinase (PKR) by sunitinib impairs antiviral innate immunity. J Biol Chem (2011) 286:26319-26. doi:10.1074/jbc.M111.253443

87. Kottke T, Hall G, Pulido J, Diaz RM, Thompson J, Chong H, et al. Antiangiogenic cancer therapy combined with oncolytic virotherapy leads to regression of established tumors in mice. J Clin Invest (2010) 120:1551-60. doi:10.1172/ JCI41431

88. Jha BK, Dong B, Nguyen CT, Polyakova I, Silverman RH. Suppression of antiviral innate immunity by sunitinib enhances oncolytic virotherapy. Mol Ther (2013) 21:1749-57. doi:10.1038/mt.2013.112

89. Hou W, Chen H, Rojas J, Sampath P, Thorne SH. Oncolytic vaccinia virus demonstrates antiangiogenic effects mediated by targeting of VEGF. Int J Cancer (2014) 135:1238-46. doi:10.1002/ijc.28747

90. Breitbach CJ, Paterson JM, Lemay CG, Falls TJ, Mcguire A, Parato KA, et al. Targeted inflammation during oncolytic virus therapy severely compromises tumor blood flow. Mol Ther (2007) 15:1686-93. doi:10.1038/sj.mt.6300215

91. Liu TC, Hwang T, Park BH, Bell J, Kirn DH. The targeted oncolytic poxvirus JX594 demonstrates antitumoral, antivascular, and anti-HBV activities in patients with hepatocellular carcinoma. Mol Ther (2008) 16:1637-42. doi:10.1038/mt. 2008.143

92. Breitbach CJ, Arulanandam R, De Silva N, Thorne SH, Patt R, Daneshmand $\mathrm{M}$, et al. Oncolytic vaccinia virus disrupts tumor-associated vasculature in humans. Cancer Res (2013) 73:1265-75. doi:10.1158/0008-5472.CAN-122687

93. Magnani L, Eeckhoute J, Lupien M. Pioneer factors: directing transcriptional regulators within the chromatin environment. Trends Genet (2011) 27:465-74. doi:10.1016/j.tig.2011.07.002

94. Picaud S, Bardot B, De Maeyer E, Seif I. Enhanced tumor development in mice lacking a functional type I interferon receptor. J Interferon Cytokine Res (2002) 22:457-62. doi:10.1089/10799900252952244

95. Dunn GP, Koebel CM, Schreiber RD. Interferons, immunity and cancer immunoediting. Nat Rev Immunol (2006) 6:836-48. doi:10.1038/nri1961

96. Uno K, Hirosaki M, Kakimi K, Tominaga M, Suginoshita Y, Hasegawa G, et al. Impaired IFN-alpha production and the risk of cancer development. J Interferon Cytokine Res (2007) 27:1013-7. doi:10.1089/jir.2007.0047

97. Stojdl DF, Lichty BD, Tenoever BR, Paterson JM, Power AT, Knowles S, et al. VSV strains with defects in their ability to shutdown innate immunity are potent systemic anti-cancer agents. Cancer Cell (2003) 4:263-75. doi:10.1016/S1535-6108(03)00241-1 
98. Naka K, Abe K, Takemoto K, Dansako H, Ikeda M, Shimotohno K, et al. Epigenetic silencing of interferon-inducible genes is implicated in interferon resistance of hepatitis C virus replicon-harboring cells. J Hepatol (2006) 44:869-78. doi:10.1016/j.jhep.2006.01.030

99. Nguyen TL, Abdelbary H, Arguello M, Breitbach C, Leveille S, Diallo JS, et al. Chemical targeting of the innate antiviral response by histone deacetylase inhibitors renders refractory cancers sensitive to viral oncolysis. Proc Natl Acad Sci U S A (2008) 105:14981-6. doi:10.1073/pnas.0803988105

100. Fang TC, Schaefer U, Mecklenbrauker I, Stienen A, Dewell S, Chen MS, et al. Histone $\mathrm{H} 3$ lysine 9 di-methylation as an epigenetic signature of the interferon response. J Exp Med (2012) 209:661-9. doi:10.1084/jem.20112343

101. Chen Q, Denard B, Huang H, Ye J. Epigenetic silencing of antiviral genes renders clones of Huh-7 cells permissive for hepatitis C virus replication. J Virol (2013) 87:659-65. doi:10.1128/JVI.01984-12

102. Cho H, Proll SC, Szretter KJ, Katze MG, Gale M Jr, Diamond MS. Differential innate immune response programs in neuronal subtypes determine susceptibility to infection in the brain by positive-stranded RNA viruses. Nat Med (2013) 19:458-64. doi:10.1038/nm.3108

103. Chang HM, Paulson M, Holko M, Rice CM, Williams BR, Marie I, et al. Induction of interferon-stimulated gene expression and antiviral responses require protein deacetylase activity. Proc Natl Acad Sci U S A (2004) 101:9578-83. doi:10.1073/pnas.0400567101

104. Katsura T, Iwai S, Ota Y, Shimizu H, Ikuta K, Yura Y. The effects of trichostatin A on the oncolytic ability of herpes simplex virus for oral squamous cell carcinoma cells. Cancer Gene Ther (2009) 16:237-45. doi:10.1038/cgt.2008.81

105. Liu TC, Castelo-Branco P, Rabkin SD, Martuza RL. Trichostatin A and oncolytic HSV combination therapy shows enhanced antitumoral and antiangiogenic effects. Mol Ther (2008) 16:1041-7. doi:10.1038/mt.2008.58

106. Otsuki A, Patel A, Kasai K, Suzuki M, Kurozumi K, Chiocca EA, et al. Histone deacetylase inhibitors augment antitumor efficacy of herpes-based oncolytic viruses. Mol Ther (2008) 16:1546-55. doi:10.1038/mt.2008.155

107. Alvarez-Breckenridge CA, Yu J, Price R, Wei M, Wang Y, Nowicki MO, et al. The histone deacetylase inhibitor valproic acid lessens NK cell action against oncolytic virus-infected glioblastoma cells by inhibition of STAT5/T-BET signaling and generation of gamma interferon. J Virol (2012) 86:4566-77. doi:10.1128/JVI.05545-11

108. MacTavish H, Diallo JS, Huang B, Stanford M, Le Boeuf F, De Silva N, et al. Enhancement of vaccinia virus based oncolysis with histone deacetylase inhibitors. PLoS One (2010) 5:e14462. doi:10.1371/journal.pone.0014462

109. Bridle BW, Chen L, Lemay CG, Diallo JS, Pol J, Nguyen A, et al. HDAC inhibition suppresses primary immune responses, enhances secondary immune responses, and abrogates autoimmunity during tumor immunotherapy. $\mathrm{Mol}$ Ther (2013) 21:887-94. doi:10.1038/mt.2012.265

110. Cedar H, Bergman Y. Linking DNA methylation and histone modification: patterns and paradigms. Nat Rev Genet (2009) 10:295-304. doi:10.1038/nrg2540

111. Okemoto K, Kasai K, Wagner B, Haseley A, Meisen H, Bolyard C, et al. DNA demethylating agents synergize with oncolytic HSV1 against malignant gliomas. Clin Cancer Res (2013) 19:5952-9. doi:10.1158/1078-0432.CCR-123588

112. Wong KK, Engelman JA, Cantley LC. Targeting the PI3K signaling pathway in cancer. Curr Opin Genet Dev (2010) 20:87-90. doi:10.1016/j.gde.2009.11.002

113. Uddin S, Fish EN, Sher DA, Gardziola C, White MF, Platanias LC. Activation of the phosphatidylinositol 3-kinase serine kinase by IFN-alpha. J Immunol (1997) 158:2390-7.

114. Martini M, Ciraolo E, Gulluni F, Hirsch E. Targeting PI3K in cancer: any good news? Front Oncol (2013) 3:108. doi:10.3389/fonc.2013.00108

115. Vlahos CJ, Matter WF, Hui KY, Brown RF. A specific inhibitor of phosphatidylinositol 3-kinase, 2-(4-morpholinyl)-8-phenyl-4H-1-benzopyran-4one (LY294002). J Biol Chem (1994) 269:5241-8.

116. Kanai R, Wakimoto H, Martuza RL, Rabkin SD. A novel oncolytic herpes simplex virus that synergizes with phosphoinositide 3-kinase/Akt pathway inhibitors to target glioblastoma stem cells. Clin Cancer Res (2011) 17:3686-96. doi:10.1158/1078-0432.CCR-10-3142

117. Tong Y, Zhu W, Huang X, You L, Han X, Yang C, et al. PI3K inhibitor LY294002 inhibits activation of the Akt/mTOR pathway induced by an oncolytic adenovirus expressing TRAIL and sensitizes multiple myeloma cells to the oncolytic virus. Oncol Rep (2014) 31:1581-8. doi:10.3892/or.2014.3020
118. Kaur S, Lal L, Sassano A, Majchrzak-Kita B, Srikanth M, Baker DP, et al. Regulatory effects of mammalian target of rapamycin-activated pathways in type I and II interferon signaling. J Biol Chem (2007) 282:1757-68. doi:10.1074/jbc.M607365200

119. Lukashev AN, Fuerer C, Chen MJ, Searle P, Iggo R. Late expression of nitroreductase in an oncolytic adenovirus sensitizes colon cancer cells to the prodrug CB1954. Hum Gene Ther (2005) 16:1473-83. doi:10.1089/hum.2005.16.1473

120. Jiang ZK, Johnson M, Moughon DL, Kuo J, Sato M, Wu L. Rapamycin enhances adenovirus-mediated cancer imaging and therapy in pre-immunized murine hosts. PLoS One (2013) 8:e73650. doi:10.1371/journal.pone.0073650

121. Fu X, Tao L, Rivera A, Zhang X. Rapamycin enhances the activity of oncolytic herpes simplex virus against tumor cells that are resistant to virus replication. Int J Cancer (2011) 129:1503-10. doi:10.1002/ijc.25808

122. Alain T, Lun X, Martineau Y, Sean P, Pulendran B, Petroulakis E, et al. Vesicular stomatitis virus oncolysis is potentiated by impairing mTORC1-dependent type I IFN production. Proc Natl Acad Sci U S A (2010) 107:1576-81. doi:10.1073/pnas.0912344107

123. Stanford MM, Barrett JW, Nazarian SH, Werden S, Mcfadden G. Oncolytic virotherapy synergism with signaling inhibitors: rapamycin increases myxoma virus tropism for human tumor cells. J Virol (2007) 81:1251-60. doi:10.1128/ JVI.01408-06

124. Zemp FJ, Lun X, Mckenzie BA, Zhou H, Maxwell L, Sun B, et al. Treating brain tumor-initiating cells using a combination of myxoma virus and rapamycin. Neuro Oncol (2013) 15:904-20. doi:10.1093/neuonc/not035

125. Diallo JS, Le Boeuf F, Lai F, Cox J, Vaha-Koskela M, Abdelbary H, et al. A high-throughput pharmacoviral approach identifies novel oncolytic virus sensitizers. Mol Ther (2010) 18:1123-9. doi:10.1038/mt.2010.67

126. Kiviharju TM, Lecane PS, Sellers RG, Peehl DM. Antiproliferative and proapoptotic activities of triptolide (PG490), a natural product entering clinical trials, on primary cultures of human prostatic epithelial cells. Clin Cancer Res (2002) 8:2666-74.

127. Kitzen JJ, De Jonge MJ, Lamers CH, Eskens FA, Van Der Biessen D, Van Doorn L, et al. Phase I dose-escalation study of F60008, a novel apoptosis inducer, in patients with advanced solid tumours. Eur J Cancer (2009) 45:1764-72. doi:10.1016/j.ejca.2009.01.026

128. Wong KF, Yuan Y, Luk JM. Tripterygium wilfordii bioactive compounds as anticancer and anti-inflammatory agents. Clin Exp Pharmacol Physiol (2012) 39:311-20. doi:10.1111/j.1440-1681.2011.05586.x

129. Zhou ZL, Yang YX, Ding J, Li YC, Miao ZH. Triptolide: structural modifications, structure-activity relationships, bioactivities, clinical development and mechanisms. Nat Prod Rep (2012) 29:457-75. doi:10.1039/c2np00088a

130. Ben Yebdri F, Van Grevenynghe J, Tang VA, Goulet ML, Wu JH, Stojdl DF, et al. Triptolide-mediated inhibition of interferon signaling enhances vesicular stomatitis virus-based oncolysis. Mol Ther (2013) 21:2043-53. doi:10.1038/mt. 2013.187

131. Quintas-Cardama A, Vaddi K, Liu P, Manshouri T, Li J, Scherle PA, et al. Preclinical characterization of the selective JAK1/2 inhibitor INCB018424: therapeutic implications for the treatment of myeloproliferative neoplasms. Blood (2010) 115:3109-17. doi:10.1182/blood-2009-04-214957

132. Mesa RA, Yasothan U, Kirkpatrick P. Ruxolitinib. Nat Rev Drug Discov (2012) 11:103-4. doi:10.1038/nrd3652

133. Quintas-Cardama A, Kantarjian H, Cortes J, Verstovsek S. Janus kinase inhibitors for the treatment of myeloproliferative neoplasias and beyond. Nat Rev Drug Discov (2011) 10:127-40. doi:10.1038/nrd3264

134. Verstovsek S, Kantarjian H, Mesa RA, Pardanani AD, Cortes-Franco J, Thomas DA, et al. Safety and efficacy of INCB018424, a JAK1 and JAK2 inhibitor, in myelofibrosis. NEngl JMed (2010) 363:1117-27. doi:10.1056/NEJMoa1002028

135. Escobar-Zarate D, Liu YP, Suksanpaisan L, Russell SJ, Peng KW. Overcoming cancer cell resistance to VSV oncolysis with JAK1/2 inhibitors. Cancer Gene Ther (2013) 20:582-9. doi:10.1038/cgt.2013.55

136. Paglino JC, van den Pol AN. Vesicular stomatitis virus has extensive oncolytic activity against human sarcomas: rare resistance is overcome by blocking interferon pathways. J Virol (2011) 85:9346-58. doi:10.1128/JVI.00723-11

137. Heinrich B, Goepfert K, Delic M, Galle PR, Moehler M. Influence of the oncolytic parvovirus H-1, CTLA-4 antibody tremelimumab and cytostatic drugs on the human immune system in a human in vitro model of colorectal cancer cells. Onco Targets Ther (2013) 6:1119-27. doi:10.2147/OTT.S49371 
138. Zamarin D, Holmgaard RB, Subudhi SK, Park JS, Mansour M, Palese P, et al. Localized oncolytic virotherapy overcomes systemic tumor resistance to immune checkpoint blockade immunotherapy. Sci Transl Med (2014) 6:226ra232. doi:10.1126/scitranslmed.3008095

Conflict of Interest Statement: The authors declare that the research was conducted in the absence of any commercial or financial relationships that could be construed as a potential conflict of interest.

Received: 21 May 2014; accepted: 07 July 2014; published online: 23 July 2014.
Citation: Forbes NE, Krishnan R and Diallo J-S (2014) Pharmacological modulation of anti-tumor immunity induced by oncolytic viruses. Front. Oncol. 4:191. doi: 10.3389/fonc. 2014.00191

This article was submitted to Tumor Immunity, a section of the journal Frontiers in Oncology.

Copyright (C) 2014 Forbes, Krishnan and Diallo. This is an open-access article distributed under the terms of the Creative Commons Attribution License (CC BY). The use, distribution or reproduction in other forums is permitted, provided the original author(s) orlicensor are credited and that the original publication in this journal is cited, in accordance with accepted academic practice. No use, distribution or reproduction is permitted which does not comply with these terms. 